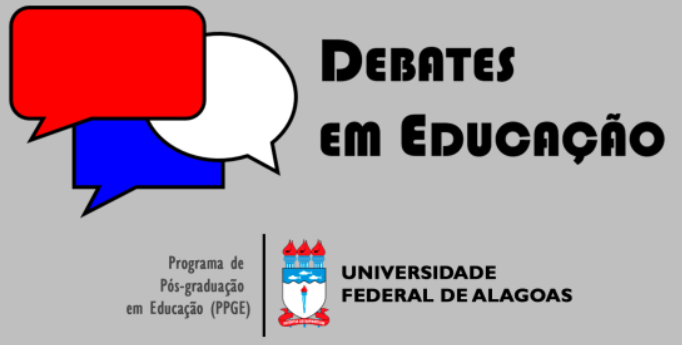

ISSN Eletrônico 2175-6600

Vol. 12 | No. 27 | Maio/Ago. | 2020

Victor Montalvão Moreno

9 iD

Universidade Federal da Bahia (UFBA)

legrandemonta@gmail.com

Emanuele Maria Leite Suzart

(9) iD

Universidade Federal da Bahia (UFBA) emanuele.su@gmail.com

William de Souza Santos

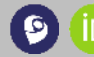

Afiliação Instituto Federal da Paraíba (IFPB) william.tenor@gmail.com

\section{ENSINO PARA O ANTROPOCENO: UMA PROPOSTA DE SEQUÊNCIA DIDÁTICA PARA O ENSINO DE REDES ECOLÓGICAS ATRAVÉS DO JOGO RAIN WORLD}

\section{RESUMO}

Nos últimos séculos desta era geológica, denominada por alguns pesquisadores de Antropoceno, as interferências nos ecossistemas vêm gerando inúmeras consequências devastadoras para as diversas formas de vida existentes no planeta. Por esse motivo, cada vez mais se faz necessário discutir tais temáticas na formação das populações, como forma de conscientização e de diminuição dos impactos causados pelo homem. Nesse intuito, o objetivo deste artigo é propor uma sequência didática que evidencia a utilização do jogo Rain World na discussão de problemas que envolvem redes biológicas. Para tanto, é utilizada uma abordagem qualitativa que apresenta o jogo Rain World e seus potenciais no ensino de Ecologia e Redes Ecológicas. Como resultado, é apresentada a sequência didática que considera as perspectivas da Aprendizagem Baseada em Problemas (ABP, do inglês Problem Based Learning, PBL) e Digital Game-Based Learning (DGBL).

Palavras-chave: Ensino de Biologia. Rain World. Antropoceno. Redes Ecológicas. ABP.

\section{TEACHING FOR THE ANTHROPOCENE: A PROPOSAL FOR DIDATIC SEQUENCE FOR TEACHING ECOLOGICAL NETWORKS THROUGH THE RAIN WORLD GAME}

\begin{abstract}
In the last centuries of this geological era, called by some researchers of Anthropocene, the interferences in the ecosystems have been generating countless devastating consequences for the diverse forms of life existing in the planet. For this reason, it is increasingly necessary to discuss such topics in the formation of populations, as a way of raising awareness and reducing the impacts caused by man. To this end, the objective of this article is to propose a didactic sequence that highlights the use of the game Rain World in the discussion of problems involving biological networks. For that, a qualitative approach is used that presents the game Rain World and its potentials in the teaching of Ecology and Ecological Networks. As a result, the didactic sequence that considers the perspectives of Problem Based Learning (PBL) and Digital Game-Based Learning (DGBL) is presented.
\end{abstract}

Keywords: Biology Teaching. Rain World. Anthropocene. Ecological Networks. PBL.

Submetido em: 19/09/2019

Aceito em: 06/02/2020

Publicado em: 22/06/2020

do http://dx.doi.org/10.28998/2 175-6600.2020v12n27p576-592 


\section{INTRODUÇÃO}

A quantidade de modificações que nós, seres humanos, produzimos no mundo tem sugerido um consenso: a era do homem moderno e da mulher moderna é uma nova era na história do planeta Terra. Para alguns, uma nova era geológica que vem sendo denominada de Antropoceno (THE ECONOMIST, 20 II). O que este conceito tenta capturar é o impacto dominante que ações humanas têm nos ecossistemas, inclusive naqueles ermos, alterando todo o funcionamento dinâmico do nosso planeta, bem como as inúmeras consequências para as formas de vida do nosso planeta, incluindo nós mesmos e nossa relação com o ambiente no qual estamos inseridos (MALHI, 2017).

Reconhecer o Antropoceno perpassa inexoravelmente por um chamado à ação: o reconhecimento do impacto que nosso estilo de vida tem causado ao planeta e que um novo ponto de equilíbrio está prestes a surgir, alheio ou não à garantia da nossa sobrevivência e manutenção desse zeitgeist'e seu modo de vida característico (BYBEE, 1991; HODSON, 20II, VILCHEZ et al., 20II). Segundo Malhi e colaboradores (20 I4), no que eles chamam de "gargalo do antropoceno inicial", as ações tomadas coletivamente pela sociedade atual são determinantes para qual possibilidade de tipo de funcionamento ecossistêmico deixaremos para as próximas gerações - um que garanta a sobrevivência delas ou não.

Tanta responsabilidade sobre os ombros reflete numa pressão para medidas práticas que reflitam em modificações diretas na maneira de como interagimos sociopoliticamente com nossa realidade. Entretanto, essa mesma realidade encontra-se mais caótica, complexa e contraditória (SARDAR, 20I0), aumentando o desafio de formar - bem como nos transformarmos em - sujeitos socioambientalmente implicados

A pergunta que emerge é: como contribuir para a formação de cidadãos e cidadãs não apenas do Antropoceno, mas para o Antropoceno? Precisamos não apenas de sujeitos capacitados a lidar com este novo mundo em que estão inseridos, mas também produzir uma nova geração de cientistas capazes de responder e de elencar questões mais complexas (LESH, 2006; HODSON, 20 I I).

Dentro da perspectiva de formação para o campo do ensino de ciências, e da mudança de paradigmas quanto à forma de seu ensino, DeBoer (199|) define que o debate sobre modificações de natureza mais prática no sistema educacional divide-se entre modificações nos requerimentos disciplinares, o que ensinar, e, nas considerações educacionais, como ensinar. Aqui, buscamos nos distanciar do vício comum à área de pesquisa-ensino de proposições excessivamente teóricas, distantes de aplicações práticas mais próximas da realidade da sala de aula.

\footnotetext{
1é um termo alemão cuja tradução significa espírito da época, espírito do tempo ou sinal dos tempos.
} 
Nesse sentido, o presente artigo tem como objetivo propor uma sequência didática que evidencia a utilização do jogo Rain World, discutindo problemas ecológicos como, por exemplo, o fluxo de matéria e de energia nos ecossistemas e as interações biológicas que envolvem redes biológicas. Tal intervenção parte da interação dos alunos com um jogo digital comercial, considerando os potenciais da Digital GameBased Learning (DGBL) (PRENSKY, 20I2), perpassando pelo ensino de cadeias e teias alimentares dentro do tópico de ecossistemas, considerando o ponto de vista disciplinar voltado para a dimensão conceitual do conteúdo conforme (ZABALA, 1998) delineia.

Juntamente com isso, será aplicada uma perspectiva referenciada da teoria de redes aplicada à ecologia (EKLÖF; ALLESINA; 20 I2). Enquanto proposta pedagógica para ensinar o conteúdo em questão, utilizaremos a Aprendizagem Baseada em Problemas (ABP, ou PBL do inglês Problem-Based Learning) que se caracteriza por ser uma metodologia na qual a aprendizagem é centrada no aluno, onde o professor se comporta como tutor agindo na função de orientação e a construção do conhecimento se dá partindo do conhecimento grupal para o individual (HMELO-SILVER, 2004). O impacto dessa estratégia no ensino já foi demonstrado por inúmeros trabalhos como os de(i.e. NORMAN; SCHMIDT, I 992; WALKER; LEARY, 2009; SCHMIDT; ROTGANS; YEW, 20II).

Na próxima seção, apresentaremos cada um desses pontos de maneira mais aprofundada e clara em seções específicas. Traremos a posteriori uma proposta de intervenção pedagógica, na forma de uma sequência didática, a fim de exemplificar a aplicação dessa interface que construímos. Com isso, o presente trabalho pretende suscitar nos leitores e leitoras a reflexão sobre a aplicabilidade, a partir de interfaces teóricas, desses referenciais na prática educacional voltada para provocar nos estudantes a reflexão e ação sobre esta epoch, o Antropoceno, na qual estamos todos inseridos.

\section{ENSINO DE CIÊNCIAS E SUAS INTERFACES}

\section{I Ensino de ecologia e redes ecológicas}

É impossível falar de ciência sem falar de tecnologia e sociedade. A ciência não existe alheia à sociedade e não pode ser entendida dessa forma (PEREZ et al., 200 I). Dentro do ensino de ciências, esse entendimento refletiu nas pesquisas com relações Ciência, Tecnologia e Sociedade (CTS). Conforme revisto por Pedretti e Nazir (20 I I), a discussão sobre relações CTS começa a surgir no campo do ensino de ciências na década de 70 e se ramifica em uma série de correntes metodológicas. Educação CTS é, portanto, um termo "guarda-chuva" que abarca diferentes correntes que buscam teorizar a respeito das conexões entre ciência, tecnologia e sociedade (PEDRETTI, 1997). Essas correntes compartilham as características de estarem centradas em práticas baseadas em questões, via de regra questões próximas à 
realidade dos estudantes (PEDRETTI, 2004), mas para reproduzirmos uma imagem ainda mais factual destas relações falta uma letra nessa sigla.

Analisar essas complexas relações sem levar em consideração o impacto delas no ambiente que as sustenta é, além de irresponsável, impossível. Nas palavras de Sander e colaboradores (2006, p. II9, tradução dos autores), "no ensino de biologia, os temas de ecologia desempenham um importante papel em contribuir para lidar com a natureza de forma responsável". A incorporação da letra A na sigla CTS[A] parte justamente deste anseio de dar maior ênfase no ensino de ciências das questões ambientais e fomentar uma visão crítica integrada, atrelando nossas ações às questões ambientais críticas que nossa sociedade vem enfrentando (VILCHES; GIL-PÉREZ; PRAIA, 20I I). Essa mudança de paradigma pode ser explicada não só pelas escancaradas consequências do nosso modo de vida, mas também pelo montante de conhecimento produzido pelas pesquisas nas áreas ambientais nas últimas décadas (KORFIATIS, 2005; VILCHES; GIL-PÉREZ; PRAIA., 20I I).

Entretanto, o ensino de ecologia que deveria ser ferramenta fundamental para a educação ambiental encontra fortes limitações ao reproduzir uma imagem de suposta neutralidade e objetividade da ciência bem como, por consequência, das relações ecossistêmicas (KORFIATIS, 2005). Além de reproduzir esse positivismo ingênuo, o ensino de ecologia tem falhado em beber nas mais novas descobertas da ciência da aprendizagem como o que tange, por exemplo, à metacognição, raciocínio de perito, concepções equivocadas usuais e estágios de desenvolvimentos em adultos (D'AVANZO, 2003).

Como defendido por Jordan e colaboradores (2009), uma alfabetização ecológica é fundamental para a formação cidadã; não apenas nos aspectos de como se posicionar criticamente diante do Antropoceno e suas mudanças, numa escala macro, mas também pelas vantagens que aprender ecologia oferece para os estudantes modificarem sua maneira de refletir sobre o mundo e seu papel nele. A alfabetização ecológica consiste em promover no público geral certo nível de conhecimento sobre ecologia, uma empreitada bem menos simples do que parece à primeira vista. Um passo para promovêla é que façamos uma transição epistemológica no ensino de ecologia de uma perspectiva positivista ingênua para uma posição pós-positivista, que seja capaz de abarcar a complexidade social e ambiental inerente ao tema.O pós-positivismo é definido por alguns autores como o positivismo contemporâneo que emerge para atenuar as críticas levantadas por filósofos da ciência como Popper, Kuhn e Feyerabend sem abdicar de sua perspectiva básica de modelo de produção de conhecimento (CROTTY, 1998).

Que essa discussão não deve se encerrar na pesquisa acadêmica, ninguém discordaria, mas uma proposta mais polêmica seria não apenas que deixemos esses entendimentos transbordarem os muros da academia, mas que estejamos também dispostos a beber das fontes culturais mais pop, que disseminam sua influência cotidiana na vida dos estudantes. Tal possibilidade se apresenta bastante estimulante, na medida em que permitiria que tratemos das relações CTSA de maneira empolgante e envolvente de 
pontos de partida já considerados pelos estudantes como estimulantes, como filmes, programas de TV seriados e jogos digitais. Foquemos nesses últimos.

\subsection{Digital Game-Based Learning}

A Aprendizagem Baseada em Jogos Digitais (Digital Game-Based Learning - DGBL), segundo Prensky (2012), consiste em reconhecer que os games são capazes de proporcionar aprendizagem em vários âmbitos; não apenas na educação, mas em distintos espaços. Autores como Jenkins et. al. (2008), Gee (2004) e Lacasa (20 I I) sinalizam que a interação com os jogos digitais auxiliam no letramento digital, no trabalho com as habilidades e com os conteúdos curriculares e extracurriculares, desta forma, possibilitando aos alunos melhorarem suas habilidades e competências.

Os jogos digitais mobilizam diversos tipos de consumidores, em virtude da atividade de jogar em si e, em especial, pela vivência proporcionada aos jogadores através das sensações de tensão, aventura, adrenalina e desafio, e pelo o fato de envolvê-los em uma atividade divertida e prazerosa, seja sozinho ou com outros jogadores (FERNANDES; RIBEIRO, 20I8). Essas sensações podem ser aproveitadas em contextos educacionais, no sentido de ampliarem seu dinamismo e engajamento.

É importante ressaltar que os jogos digitais são os artefatos tecnológicos mais utilizados na sociedade contemporânea (ALVES, 20 I2; ALEXANDRE; SABATINI, 20I3) e o aumento de seu uso devese concomitantemente à grande facilidade de acesso ao computador, dispositivos móveis e a internet (FERNANDES; RIBEIRO, 20I8) ofertados para a população. Pessoas de diversas idades são vistas com frequência jogando nos smartphones, entre outras atividades do cotidiano. A relevância e a adesão dos jogos digitais na sociedade são tão significativas que sua indústria de entretenimento é considerada uma das maiores do mundo (ALVES; RIOS; CALBO, 20I3).

Considerando tais potenciais encontrados nos jogos digitais, diversos pesquisadores têm utilizado tanto os jogos comerciais como os educacionais em suas práticas educacionais. São exemplos disso: o jogo In Situ, onde o jogador auxilia os leucócitos na proteção das células contra vírus e bactérias que invadem a corrente sanguínea (SOUZA; COSTA SILVA; ALVES, 20I3); o jogo Pokémon-Go, onde através da evolução dos pokémons pode ser abordada a evolução biológica das espécies (LOPES; LOPES, 20 I7); o jogo CSI: The experience que pode evidenciar a genética (BEIER; MILLER; WANG, 20 I2); o jogo Calangos que explora a ecologia (MACHADO, 20 I 5), entre outros. Inspirados nessas práticas envolvendo os jogos digitais e ensino de ciências, buscamos um jogo que pudesse trazer a discussão sobre redes ecológicas como forma de suscitar aprendizagens sobre ecossistemas e a ação do homem neste meio. Esse jogo é o Rain World, apresentado a seguir. 


\subsection{O Rain World}

Desenvolvido pela Videocult, publicado pela Adult Swin Games e tendo sido lançado em 20।4, o Rain World é um jogo comercial, compatível com os sistemas Steam, Nintendo Switch e PlayStation 4, para uso por apenas um jogador, com classificação para maiores de 13 anos.

Rain World é um jogo de sobrevivência de plataforma baseado em física que se passa num amplo mundo abandonado, tomado por diferentes criaturas. $\bigcirc$ seu mundo do jogo retrata um ecossistema sombrio e úmido onde uma chuva intensa é capaz de quebrar seus ossos e triturar a superfície regularmente, tornando a vida como conhecemos impossível; mas não outras formas de vida. Os animais desse cenário hibernam para escapar dos temporais devastadores durante longos períodos, mas passam os períodos de seca entre as chuvas, buscando desesperadamente comida para durar mais um dia.

O gamer interpretará o papel de um solitário e nômade Slugcat (ou gato lesma). Separado de sua família, ele deve explorar o ecossistema, achar comida e abrigos para sobreviver às chuvas e evitar as sempre presentes ameaças tanto do ambiente quanto aos predadores que espreitam por essas estranhas paisagens. No ecossistema, alterna entre o papel de um predador onívoro, podendo caçar morcegos, insetos e colher frutas para comer, com também o de presa, pois pode ser caçado por espécies terrestres e aéreas com diferentes estratégias de caça.

Este game apresenta um grande potencial pedagógico que reside no cerne da sua centelha de criação. Na tentativa de criar um cenário selvagem e envolvente, seus criadores se inspiraram em interações ecológicas reais, inclusive simulando dinâmicas de equilibrio, entre as relações de predadorpresa. Embora obviamente essas interações tenham sido moduladas pela necessidade de jogabilidade e limitações da plataforma, as interações ecológicas representadas no Rain World podem ser usadas como um modelo pedagógico para o estudo de redes ecológicas. De maneira intuitiva o jogo projeta o jogador no papel de um predador base de uma ampla cadeia alimentar, uma espécie central na rede ecológica local. O entendimento dessas relações ecológicas é vital para compreendermos nosso papel cidadão diante desta sociedade de consumo central para o Antropoceno.

\subsection{Ensino de Ecologia e Redes Ecológicas}

O ensino de ecologia e a educação ambiental por si só já representam um tópico de suma relevância para a maneira como qualquer cidadão/cidadã irá lidar com as questões do Antropoceno (JORDAN et al., 2009). O ensino de ecologia tem encarado inúmeros desafios, como aplicar as novas descobertas da ciência da aprendizagem no ensino (D'AVANZO, 2005) além das novas descobertas da 
própria ciência da ecologia (KORFIATIS, 2005). Como levantamos anteriormente, é necessária uma transição epistemológica no ensino de ecologia para superar esses desafios.

A teoria de redes (ou de grafos) se encontra bem posicionada para contribuir para essa transição e tem sido frutiferamente aplicada na pesquisa em ecologia (EKLÖF; ALLESINA; 20 I7). A análise de redes vem permitindo grandes avanços e trazendo à tona como redes naturais de origens diferentes podem apresentar características semelhantes - como uma rede de cadeia alimentar na savana africana, a rede mundial de computadores, uma rede neural de um Caenorhabditis elegans e a rede de atores que trabalharam juntos em Hollywood (BARABÁSI, 20|6).

Em se tratando das redes ecológicas, muitas vezes as relações ecológicas são apresentadas de maneira simplista aos estudantes, ainda que a complexidade dessas seja muito bem descrita, um dilema pedagógico entre descrições menos realistas, porém mais simples, e descrições mais realistas, porém mais complexas (CARLSSON, 2002). A análise de redes contorna esse debate ao encontrar formas simples de descrever padrões complexos, além de oferecer maneiras intuitivas de representarmos graficamente tais sistemas ecológicos, focando não apenas na dimensão estética, como nas representações básicas de livrostextos, mas nas questões relevantes como padrões relacionadas à biodiversidade e ao fluxo de energia e matéria (PASCUAL et. al., 2005). Isso pode ser particularmente relevante para o ensino, pois algumas das principais dificuldades dos estudantes com ecologia residem no tópico de ecossistemas (D'AVANZO, 2003) que poderiam ser contornadas aplicando redes. Na dificuldade em diferenciar comunidades biológicas de ecossistemas (SANDER; JELEMENSKÁ; KATTMANN, 2006), por exemplo, a perspectiva de redes simplifica a diferenciação para os estudantes, ao focar explicitamente nas funções da biodiversidade e no fluxo de energia e matéria. A construção de representações das redes já vem sendo usada com sucesso em intervenções pedagógicas, sendo os trabalhos protagonizados por Hmelo-Silver (et. al., 20 I I; et. al., 20I5) um ótimo exemplo.

Entretanto, apenas atualizar como os conceitos são apresentados não deve ser considerado suficiente para mobilizar os estudantes. A própria estrutura pedagógica deve promover dimensões variadas do conteúdo, como a procedimental, por exemplo, no sentido de estimular que os estudantes se envolvam diretamente com seu próprio aprendizado. Para tanto, trabalharemos com a ABP, a seguir apresentada de maneira complementar a seguir.

\subsection{Aprendizagem Baseada em Problemas}

A Aprendizagem Baseada em Problemas (ABP) ou, em inglês, Problem Based Learning (PBL), é uma proposta de ensino-aprendizagem que faz uso de problemas da vida real, para estimular o desenvolvimento do pensamento, as habilidades de solução de problemas e a aquisição de conceitos 
fundamentais da área de conhecimento em questão. (BARROWS, 1996; RIBEIRO, 2010). Tal proposta tem como base a aprendizagem centrada no aluno perante a orientação do professor-tutor e a construção do conhecimento individual e grupal (BARROWS, 1986; HMELO-SILVER, 2004; MALHEIRO; DINIZ, 2008; RIBEIRO, 20I0; FREITAS, 2012; SOUZA; DOURADO, 20I5). Enquanto metodologia, tem sido considerada um bom caminho para formar "solucionadores de problemas do século XXI", nas palavras de Edens (2000) e tem sido fortemente indicada no ensino de ecologia pela capacidade de envolver questões sociais, políticas e econômicas indissociáveis a questões ambientais (FARLEY et. al., 2005).

Para aplicar a ABP é necessário organizar as sessões tutoriais. Essas sessões consistem na organização dos alunos em grupos, para que o professor-tutor acompanhe a construção coletiva do conhecimento e a participação ativa dos alunos, no processo de aprendizagem (CONRADO, NUNESNETO, EL-HANI, 20।4). É nas sessões tutoriais em que são desenvolvidos e aplicados o passo a passo da ABP (CONRADO, NUNES-NETO, EL-HANI, 20I4) que compõe a trajetória a ser seguida pelos alunos. Conforme sugere Conrado e colaboradores (2013), o passo a passo é seguido em sete pontos: I) leitura do problema e esclarecimento dos termos e conceitos presentes em sua formulação; 2) definição do problema; 3) chuva de ideias (brainstorming); 4) detalhamento, explicações, sistematizando e estruturando resultados da chuva de ideias; 5) proposição de objetivos de aprendizagem autodirigida; 6) busca de informações e estudo individual; 7) avaliação.

Três aspectos são centrais para aplicação da ABP. Primeiro, a confecção do problema pelo professor ou comissão de professores responsáveis deve ser feita de maneira a produzir um problema desafiador e motivador que mobilize os estudantes para a aprendizagem (RIBEIRO, 20I0). O problema deve ser consoante com a realidade dos estudantes, remetendo a problemas reais do cotidiano dos mesmos (BARROWS, 1996), mas também ser aberto o suficiente.

Por fim, recomenda-se que o problema seja aberto, ou seja, comportando possibilidades diversas de soluções para o mesmo problema e complexo, na medida em que possibilite o entendimento dos conceitos, e permita a reflexão e a discussão sobre o que deve ser aprendido (SOUZA; DOURADOS, 20I5).

Nesta abordagem, o papel do estudante e do professor são refletidos sobre um diferente entendimento da dinâmica de sala de aula. Na ABP a instrução é centrada nos estudantes. Isso significa dizer que sua aplicabilidade centra-se na formação do aluno, através do desenvolvimento de atividades educativas que o motivem a participar ativamente, em grupo ou individualmente, de discussões e na busca da construção do conhecimento (SOUZA; DOURADOS, 20I5). Se por um lado, a ABP estimula essa participação mais ativa do aluno, por outro lado, os alunos acabam instigados a assumir a responsabilidade pela própria aprendizagem (DECKER; BOUHUIJS, 2009). Como consequência, a ABP também tem como característica desenvolver o trabalho colaborativo a partir dos grupos (SOUZA; DOURADO, 20I 5). 
O professor, por outro lado, assume na ABP a função de tutor. De acordo com Malheiros e Diniz (2008) o fazer docente nessa perspectiva sofre uma mudança drástica, pois a função de transmissor de conteúdo, passa a ser a de estimular a parceria dos estudantes na construção do conhecimento. Além disso, contribui ainda para que principios didáticos que vinculam o ensino e a aprendizagem com a situação problema, sejam desenvolvidos através do incentivo da participação, da autonomia e da responsabilidade do aluno, na realização das atividades e na construção de novas aprendizagens (SOUZA; DOURADO, 20I5).

$\mathrm{Na}$ atuação junto aos grupos, o docente deve promover a colaboração entre os membros; direcionar as discussões ao problema, a fim de evitar o desvio do foco; intervir com informações com o objetivo de ligar os conhecimentos prévios do estudante com o novo conteúdo a ser aprendido (BOROCHOVICIUS; TORTELLA, 20I4); acompanhar o processo de investigação e resolução dos problemas (SOUZA; DOURADO, 2015).

A Aprendizagem Baseada em Problemas é uma proposta desafiadora, pois ela redefine os papéis a serem desempenhados por todos os envolvidos, além de transgredir os moldes tradicionais de ensinoaprendizagem e da organização curricular existentes na maioria das escolas (BERBEL, 1998).

\section{MATERIAIS E MÉTODOS}

Após a exposiçãa das bases teóricas que fundamentaram a proposta, será apresentada a sequência didática referente ao ensino de Redes Ecológicas.Tal sequência tem como público alvo os alunos do terceiro ano do ensino médio e está baseada na Digital Game-Based Learning (DGBL), abordagem que faz uso de situações/problemas contidos no enredo e no mundo do jogo, para ancorar a aprendizagem de conteúdos e o desenvolvimento de habilidades de resolução de problemas da área de conhecimento em questão (PRENSKY, 2012).

Os conteúdos escolares escolhidos para serem trabalhados no decorrer da sequência e referenciados a partir do livro didático adotado pela escolaàsão: introdução à ecologia, teias alimentares e relações ecológicas.

Com o desdobramento da sequência, almejam-se os seguintes objetivos de aprendizagem: I) refletir sobre a relação entre biodiversidade e redes ecológicas; 2) pensar na importância de cada ser vivo na cadeia e teia alimentar; 3) identificar as causas e consequências dos desequilíbrios nas cadeias alimentares; 4) ponderar a respeito das relações ecológicas que eles mesmos estabelecem.

A sequência foi planejada para ser desenvolvida no decorrer de dez aulas de cinquenta minutos/aula, totalizando oito horas e vinte minutos de atividades. Ressalta-se que a sequência pode estar 
sujeita a reajustes, a depender do contexto de sua aplicação. Uma parte do engajamento dos estudantes se dará a partir de atividades extraclasse, como os momentos in game.

Na primeira aula, o professor deverá apresentar os objetivos e a organização da intervenção educacional e separar os grupos, de acordo com o critério que considerar mais adequado. Após essa organização inicial faz-se necessária uma introdução sobre o jogo a ser utilizado, explicitando sua mecânica para os menos familiarizados. Com o jogo tendo sido apresentado, resta ao professor apresentar o caso e o problema central que norteará as atividades, que segue abaixo.

Figura I - Caso e o problema - Slugcats à Brasileira: Os Pequenos Ícones do Sertão

\section{Slugcats à Brasileira: Os Pequenos Ícones do Sertão}

O rabo-de-facho (Trinomys yonenagae) é um pequeno mamifero que habita a caatinga junto às dunas das margens baianas do rio São Francisco. Este roedor possui uma cauda maior que o corpo, orelhas enormes e desproporcionais, patas dianteiras curtas e traseiras grandes. Quando está com pressa ou tentando escapar de seus predadores, utiliza as suas longas patas traseiras para efetuar saltos e o chicoteio da sua cauda para direcionar o sentido da locomoção para ser ágil.

Os gatos-do-mato, corujas, cobras, teiús e cachorros-do-mato são alguns dos seus predadores naturais, sendo essa espécie de roedor uma figura central na rede ecológica endêmica da região. As sementes dos araçás-de-boi e arbustos da família das goiabas são a refeição predileta do pequeno mamífero. Por essa razão, existem suspeitas de que podem ser os principais responsáveis pela distribuição e abundância dessas plantas.

Para sobreviver às temperaturas quentes do dia e frias da noite, os rabos-de-facho cavam tocas nas dunas entre bromélias e macambiras. As tocas são cavadas coletivamente e podem atingir 15 metros de extensão. Os machos e as fêmeas compartilham praticamente o mesmo espaço da toca, sem repartir o território entre eles, e comida (e talvez parceiros sexuais), e vivem em grupos com até oito adultos, além dos filhotes. Além de conviverem em sua colônia, eles visitam grupos vizinhos e contribuem para a produção de filhotes, e a cada ano alguns se mudam para grupos onde encontrem companheiros menos aparentados. As tocas construidas também acabam abrigando outros animais, como pequenos lagartos, aranhas e grilos, o que torna os rabos-de-facho importantes na manutenção do ecossistema.

A caatinga é um bioma com padrões climáticos irregulares, pois as chuvas previstas para o período de novembro e abril não ocorrem em todos os anos. Esse fato impede, do ponto de vista evolutivo, que os organismos residentes desse local concentrem funções essenciais, como a reprodução, apenas em períodos mais propícios. Não à toa as fêmeas de rabo-de-facho estão reprodutivamente ativas 0 ano todo. Espécies análogas como os Ratos-Cangurus da família Heteromydae que habitam os desertos da América do Norte apresentam adaptações fisiológicas especificas como a ausência de necessidade de ingestão de água pois vivem em ambientes mais previsiveis. A época das chuvas só é vantajosa para a sobrevivência dos filhotes de Rabo-de-Facho em razão da fartura dos frutos dos os araçás-de-boi encontradas nesse período.

Como foi visto no caso acima, os rabos-de-facho tem utilizado de diversas estratégias para sobreviverem dentro de um determinado ecossistema. Não só os rabos-de-facho como também diversas outras espécies de animais tem buscado reinventar hábitos e relações com outros animais como forma de fugir da extinção.

Partindo desse caso específico do Rabo-de-Facho, sejam bem vindos ao inverso do nosso sertão, o mundo chuvoso de Rain World. Na pele do Slugcat, vocês tentarão sobreviver sozinhos a um mundo inóspito, hostil e misterioso, como um Rabo-de-Facho perdido de sua toca. E que tal se usarmos essa experiência para aprender um pouco sobre o que significa sobreviver no nosso mundo? As próximas atividades serão focadas em resolver uma ampla questão: o que os ecossistemas artificiais deste jogo tem de semelhante e de diferente com os ecossistemas naturais nos quais estamos inseridos? Para isso, todos deverão ler a seguinte reportagem publicada na Revista Pesquisa FAPESP, "Estratégias sertanejas: Único mamífero instalado nas dunas do rio São Francisco, Rabo-deFacho se agrupa para viver". Partindo do conhecimento retirado da reportagem sobre a ecologia do Rabo-de-Facho (Trinomys yonenagae), os estudantes deverão realizar as atividades presentes na sequência didática, sempre estabelecendo paralelos entre o Slugcat e o Rabo-de-Facho.

Fonte: Fapesp ${ }^{2}$

2 https://revistapesquisa.fapesp.br/2012/04/I0/estratégias-sertanejas/ 
Em seguida, o professor deverá realizar a divisão da turma em equipes para elaboração da atividade I. Para desenvolver esta atividade, cada membro da equipe, individualmente, deve jogar o game extraclasse e, concomitantemente, construir com sua equipe uma rede ecossistêmica do bioma determinado. Cada equipe ficará responsável por uma região do mundo, ou biomas, na linguagem do jogo (Figura 2 e Figura 3).

Na segunda aula, os alunos devem expor impressões sobre o jogo, assim como as classificações que estabeleceram para as diferentes interações com a Inteligência Artificial do jogo. Após esse momento, o professor deve proporcionar uma discussão entre as classificações elaboradas pelos alunos e os conceitos técnicos da ecologia como predação e comensalismo, por exemplo. Deve ser incentivada a representação gráfica da rede de interação com a maior quantidade de detalhes possíveis e representações artísticas da arte do jogo por alunos com maior acuidade em desenho devem ser estimuladas.

Figura 2 - Visão completa dos diferentes biomas de Rain World

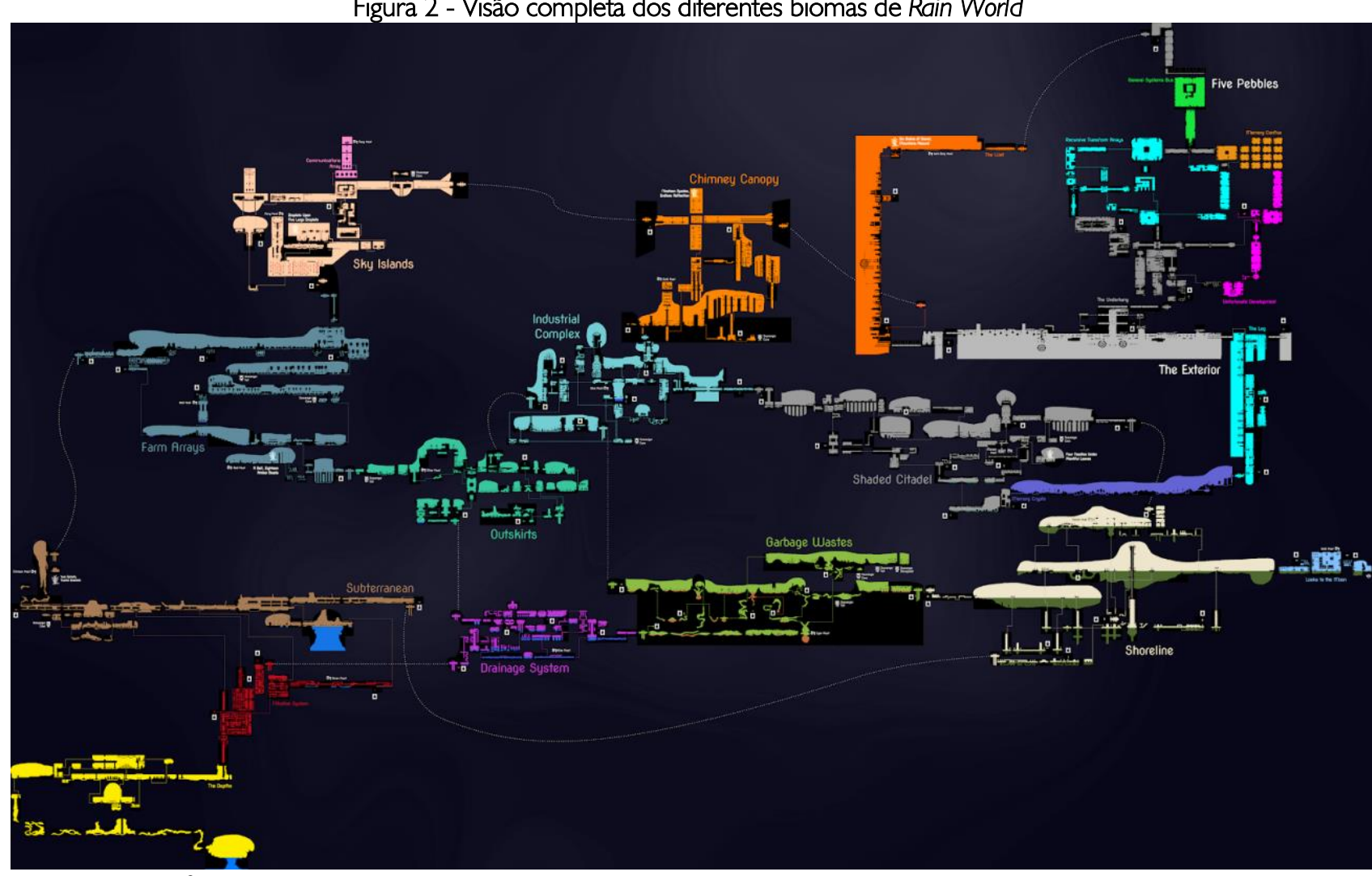

Fonte: Egg Zero3.

\footnotetext{
3 http://eggzero.serv.pink/img/rainworldmap.png- material produzido por fãs
} 
Figura 3 - Visão simplificada dos biomas, o professor deve dar preferência aos biomas de cor azul celeste ao realizar a divisão

\section{dos grupos}

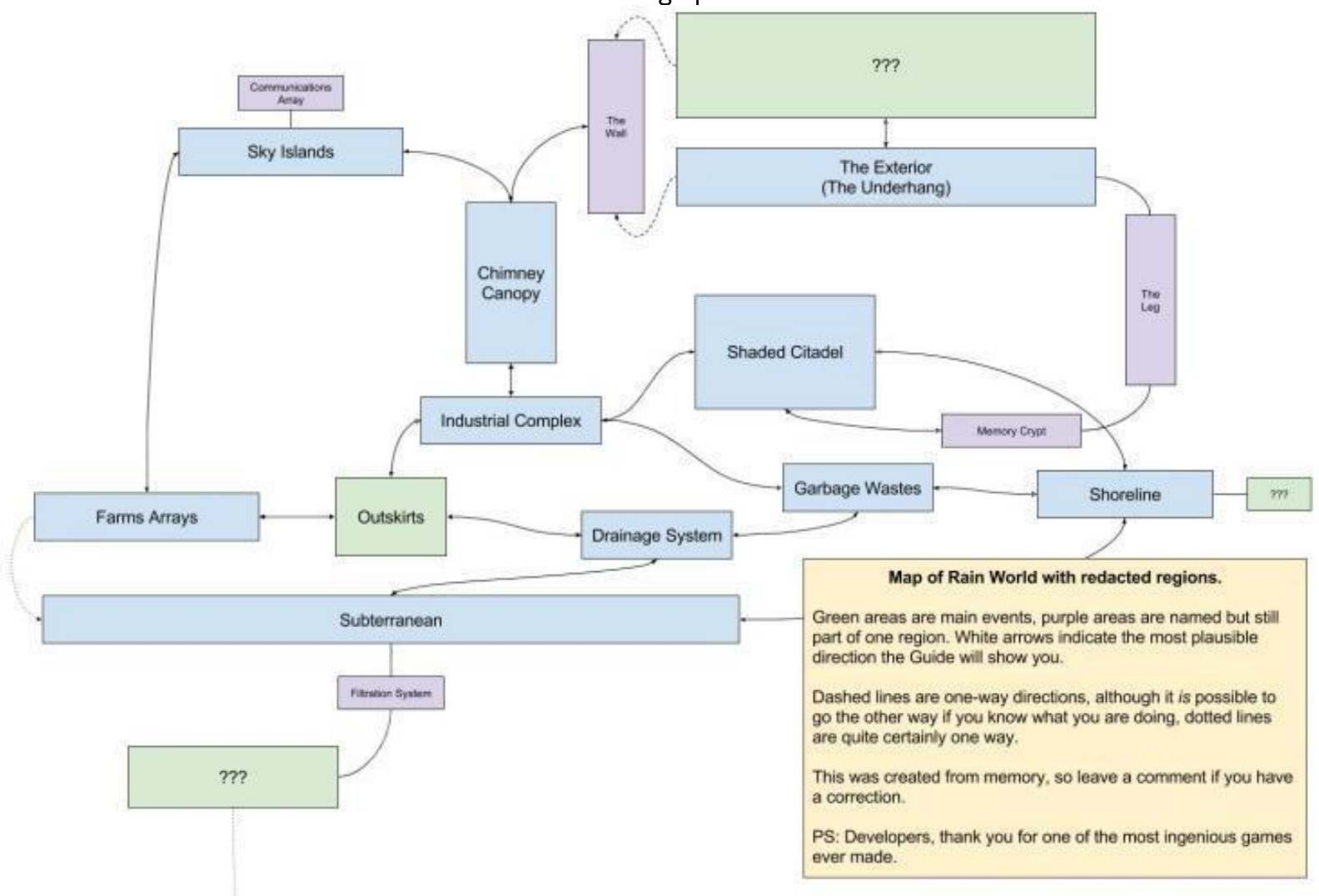

Fonte: Gamepedia 4

Na terceira aula, as equipes devem apresentar a primeira versão da atividade I. Cada grupo apresentará sua impressão sobre o bioma pelo qual ficou responsável, descrevendo a rede da melhor maneira que thes prouver. O professor deve estimular que os estudantes realizem comparação entre suas redes, levantando se as diferenças entre os biomas são significantes.

Da quarta até a sétima aula, o professor deve requisitar que os grupos realizem a atividade II, conforme a situação-problema apresentada abaixo:

\section{Figura 4 - Situação-problema}

Vocês são profissionais da área de ecologia, comportamento animal e zoologia contratados para auxiliar a produção de uma continuação para o jogo Rain World. Um dos objetivos dos contratantes é que os ecossistemas e biomas do novo jogo sejam mais realistas, daí contratarem consultoras da área de biologia para auxiliá-los. Para tanto, vocês deverão produzir um relatório que deverá:

Explicitar conceitos sobre redes ecossistêmicas de maneira que os programadores do jogo possam compreender
Sugerir uma nova rede ecossistêmica do Slugcat inspirada nas relações do Rabo-de-Facho

(Trinomys yonenagae)

Fonte: elaborado pelos autores.

${ }^{4}$ https://rainworld.gamepedia.com/Map- material produzido por fãs 
O professor deve apresentar, junto com a situação-problema, a rotina de sete passos para a resolução de um problema já apresentado aqui na seção de PBL. Os grupos devem ter a liberdade para discutir, mas o professor, como tutor, deve estimular certos questionamentos norteadores como: a rede é factível? O fluxo de energia e matéria é suficiente para manter o ecossistema estável?Qual espécie compõe a base da cadeia alimentar? Quais são os produtores? Quais são os organismos "hub" da rede?

professor deve ficar atento para resgatar as distinções que surgiram nas apresentações dos grupos, reforçando a diversidade e as limitações do jogo, como modelo de redes ecológicas. Recomendam-se mais aulas para que os estudantes se reúnam e produzam o relatório que deverá ser apresentado pelos grupos na oitava aula. Nesse momento é importante estimular o roleplay, quanto mais os estudantes entrarem no papel dos consultores, melhor.

Na nona aula,os alunos devem produzir textos dissertativos individuais sobre redes-ego e a diferenciação entre ego/eco. $\bigcirc$ professor deve apresentar uma pequena definição das redes-ego, redes centradas em um único indivíduo/organismo e requisitar que os estudantes dissertem sobre como os seres humanos se consideram o centro da natureza e se essa visão é corroborada pelo que eles aprenderam sobre redes ecossistêmicas.

Por fim, cabe ao professor garantir um espaço para que os alunos avaliem a proposta da sequência, assim como solicitar uma autoavaliação da sua participação individual e em equipe nas atividades. No decorrer da sequência didática, o docente deverá avaliar os alunos de forma contínua, através da participação do aluno, e somativa, baseada na realização das atividades. No último dia de aula da sequência, o professor recomendará uma rodada de avaliação geral da sequência com os alunos, assim como solicitará a redação de um texto breve sobre a autoavaliação de cada aluno.

\section{CONCLUSÃO}

Diante de uma realidade tão intrinsecamente imbricada, urge a disposição de pesquisadores e/ou educadores de se arriscarem no estabelecimento de pontes entre referenciais díspares. Aqui, tentamos, a partir de uma proposta de intervenção educacional, estabelecer interfaces entre jogos digitais, $\mathrm{ABP}$ e ensino de ecologia, partindo do pressuposto de que uma realidade mais conectada prescreve a necessidade de fomentar reflexões sobre nosso papel nessa teia de relações socioambientais. Tendo em vista os desdobramentos para as relações CTS[A] que a atual conjuntura, aqui denominada de Antropoceno, estabelece, foi realizada uma proposta de intervenção pedagógica na forma de uma sequência didática.

Partindo das classificações de Pedretti e Nazir (20 I I ) das correntes de CTS[A] é possível identificar que esse trabalho está consoante com a corrente de aplicação e design, cujas abordagens dominantes apresentam caráter mais criativo e pragmático. O esforço aqui realizado nessa corrente não visava apenas 
oferecer ao leitor ou leitora uma ferramenta a ser aplicada em sala de aula, para mobilizar certos conteúdos de forma ativa e inovadora. É preciso salientar que o principal esforço deste trabalho consiste em mostrar tanto para pesquisadores da área de educação quanto para professores que diferentes perspectivas teóricas podem se complementar de forma funcional e lúdica. Este esforço reflete um entendimento dos autores de que não há uma resposta simples a um problema complexo como a educação, mas uma série de respostas possíveis e complementares que apresentam contribuições importantes sobre como lidar com o desafio de educar para o Antropoceno.

Com isso, ressaltamos também com suas devidas críticas, as proposições excessivamente teóricas e redundantes, que pouco se comunicam com a realidade dos professores e estudantes (DEBOER, I99|) bem como com o excesso de especialização teórica que por vezes enrijece a pesquisa em educação (BIKNER-AHSBAHS; PREDIGER; 20 I4). Entretanto, a presente sequência didática carece de validação, o que não exclui as contribuições aqui suscitadas, mas estabelece a necessidade de continuação do presente trabalho e seu desdobramento em novas pesquisas. Esperamos com isso suscitar nos leitores semelhante disposição, bem como também servir de inspiração para novas intervenções educacionais que se predisponham a romper com lugares comuns na área de pesquisa em educação.

\section{REFERÊNCIAS}

ALEXANDRE, C.; SABBATINI, M. A contribuição dos Jogos Digitais nos processos de aprendizagem. In: $5^{\circ}$ Simpósio Hipertexto e Tecnologias na Educação, 2013, p. I - 18.

ALVES, L. Videojogos e aprendizagem: mapeando percursos. In: CARVALHO, A. Aprender na era digital Jogos e Mobile-Learning, 2012, p. II-28.

ALVES, L. R. G.; RIOS, V.; CALBO, T. Games: delineando novos percursos de interação. Revista INTERSEMIOSE, a. 12, n. 4, p. 268-293, 2013.

BARABÁSI, A. L. Vulnerability due to interconnectivity. In: BARABÁSI, A. L. et al. Network science. Cambridge university press, 2016, p. I-27.

BARROWS, H. S. Problem-based learning in medicine and beyond: a brief overview. New Directions for teaching and learning, n. 68, p. 3-12, 1996.

BEIER, M. E.; MILLER, L. M.; WANG, S. Science games and the development of scientific possible selves. Cultural Studies and Science Education, v. 7, n. 4, p. 963 - 978, 2012.

BERBEL, N. A. N. A problematização e a aprendizagem baseada em problemas: diferentes termos ou diferentes caminhos? Interface-Comunicação, Saúde, Educação, v. 2, p. 1 39- I 54, 1998.

BIKNER-AHSBAHS, A.; PREDIGER, S. (Ed.). Networking of theories as a research practice in mathematics education. Dordrecht, The Netherlands: Springer, 2014. 
BOROCHOVICIUS, E.; TORTELLA, J. C. B. Aprendizagem Baseada em Problemas: um método de ensino-aprendizagem e suas práticas educativas. Ensaio: Avaliação e Políticas Públicas em Educação, Rio de Janeiro, v. 22, n. 83, p. 263-294, 2014.

BYBEE, R. W. Planet Earth in crisis: how should science educators respond? The American Biology Teacher, v. 53, n. 3, p. |46-153, 1991.

CARLSSON, B. Ecological understanding 2: transformation-a key to ecological understanding. International Journal of Science Education, v. 24, n. 7, p. 70 I-7I 5, 2002.

CONRADO, D. M.; EL-HANI, C. N.; NUNES-NETO, N. F. Sobre a éticaambientalna formação do biólogo. Revista Eletrônica do Mestrado em Educação Ambiental (REMEA), v.30, n. I, p. I20-139, jan./jun. 2013.

CONRADO, D. M., NUNES-NETO, N. F. \& EL-HANI, C. N. Aprendizagem baseada em problemas (ABP) na educação científica como estratégia para formação do cidadão socioambiental responsável. Revista Brasileira de Pesquisa em Educação Científica, v. I4, n. 2, p. 077-087, 2014.

CROTTY, Michael. The foundations of social research: Meaning and perspective in the research process. Sage, 1998.

D'AVANZO, C. Research on learning: potential for improving college ecology teaching. Frontiers in Ecology and the Environment, v. I, n. 10, p. 533-540, 2003.

DEBOER, G. E. A History of Ideas in Science Education: implications for practice. 1234 Amsterdam Avenue, New York: NY, v. 10027, 1991.

DECKER, I. R.; BOUHUIJS, P. A. Aprendizagem baseada em problemas e metodologia da problematização. In: ARAÚJO, U. F.; SASTRE, G. (org.). Aprendizagem baseada em problemas no ensino superior. São Paulo: Summus, 2009, p. 177- 204.

EDENS, K. M. Preparing problem solvers for the 2 I st century through problem-based learning. College Teaching, v. 48, n. 2, p. 55-60, 2000.

EKLÖF A.; ALLESINA S. Network, Ecological. In: HASTINGS, A.; GROSS, L. J.(ed.) Encyclopedia of theoretical ecology. Berkeley: University of California Press, 20 I2, p. 470-509.

FARLEY, J. et al. Ecological economics: a workbook for problem-based learning. Island Press, 2005.

FERNANDES, C. W. R; RIBEIRO, E. L. P. Games, gamificação e o cenário educacional brasileiro.CIET: EnPED, p. I-22, 2018.

FREITAS, R. A. M. M. da M. Ensino por problemas:uma abordagem para o desenvolvimento do aluno. Educação e Pesquisa, São Paulo, v. 38, n. 2, p. 403-4I 8, 2012.

GEE, James Paul. Lo que nosenseñan los videojuegossobre el aprendizaje y el alfabetismo. Málaga: Aljibe, 2004.

HMELO-SILVER, C. E. Problem-based learning: what and how do students learn? Education Psycology Review, v. 16, n. 3, p. 235-266, 2004.

HMELO-SILVER, C. E. et al. Systems and Cycles: Learning about Aquatic Ecosystems. Society for Research on Educational Effectiveness, $201 \mathrm{I}$. 
HMELO-SILVER, C. E. et al. Using representational tools to learn about complex systems: A tale of two classrooms. Journal of Research in Science Teaching, v. 52, n. I, p. 6-35, 2015.

HODSON, D. Looking to the future: building a curriculum for social activism. Rotterdam: Sense Publishers, 201।.

JENKINS, H, PURUSHOTMA, R, CLINTON, K, WEIGEL,M, ROBISON, A. J. "Confronting the Challenges of Participatory Culture: Media Education for the 2 I st Century", Chicago: The MacArthur Foundation. 2008

JORDAN, R. et al. What should every citizen know about ecology? Frontiers in Ecology and the Environment, v. 7, n. 9, p. 495-500, 2009.

KORFIATIS, K. J. Environmental education and the science of ecology: exploration of an uneasy relationship. Environmental Education Research, v. I I, n. 2, p. 235-248, 2005.

LACASA, Pilar. Los videojuegos. Ediciones Morata, 2011 .

LESH, R. Modeling students modeling abilities: The teaching and learning of complex systems in education. The Journal of the Learning Sciences, v. I5, n. I, p. 45-52, 2006.

LOPES, L. A.; LOPES, P. T. C. Explorando o Pokémon GO comomodelo para o ensino de Biologia. Acta Scientiae, v. 19, n. 3, p. 517-529, 2017.

MACHADO, R. F. Usando o jogo eletrônico educacional Calangos em sala de aula para ensinar sobre nicho ecológico. 20 I5. Dissertação (Mestrado em Ensino, Filosofia e História das Ciências), Universidade Federal da Bahia, Universidade Estadual de Feira de Santana, Salvador, 2015.

MALHEIRO, J.M.; DINIZ, C. W. P. Aprendizagem baseada em problemas no ensino deciências: mudando atitudes de alunos e professores. Amazônia: Revista de Educação em Ciências e Matemáticas, v. 4, n. 8, p. I-10, 2008.

MALHI, Y. The concept of the Anthropocene. Annual Review of Environment and Resources, v. 42, p. 77- I04, 2017.

MALHI, Y. et al. Tropical forests in the Anthropocene. Annual Review of Environment and Resources, v. 39, p. 125-159, 2014.

NORMAN, G. T.; SCHMIDT, H. G. The psychological basis of problem-based learning: a review of the evidence. Academic medicine, v. 67, n. 9, p. 557-565, 1992.

PASCUAL, M. et al. (ed.). Ecological networks: linking structure to dynamics in food webs. Oxford University Press, 2006.

PEDRETTI, E. Septic tank crisis: A case study of science, technology and society education in an elementary school. International Journal of Science Education, v. 19, n. 10, p. I21 I-1230, 1997.

PEDRETTI, E. Perspectives on learning through research on critical issues-based science center exhibitions. Science Education, v. 88, n. SI, p. S34-S47, 2004.

PEDRETTI, E.; NAZIR, J. Currents in STSE education: Mapping a complex field, 40 years on. Science education, v. 95, n. 4, p. 601-626, 2011 . 
PÉREZ, D. G. et al. Para uma imagem não deformada do trabalho científico. Ciência \& Educação, v. 7, n. 2, p. I25-|53, 200|.

PRENSKY, M. Aprendizagem baseada em jogos digitais. São Paulo: SENAC, p. 575, 20 I2.

RIBEIRO, L. R. C. Aprendizagem Baseada em Problemas (PBL): uma experiência no ensino superior. São Carlos: EduFSCar, p. I5I, 20 I0.

SANDER, E.; JELEMENSKÁ, P.; KATTMANN, U. Towards a better understanding of ecology. Journal of Biological Education, v. 40, n. 3, p. 1 19-123, 2006.

SARDAR, Z. Welcome to postnormal times. Futures, v. 42, n. 5, p. 435-444, 2010.

SCHMIDT, H. G.; ROTGANS, J. I.; YEW, E. HJ. The process of problem-based learning: what works and why. Medical education, v. 45, n. 8, p. 792-806, 2011.

SOUZA, S. C. D.; DOURADO, L.Aprendizagem baseada em problemas (ABP): um método de aprendizagem inovador para o ensino educativo. HOLOS, v. 5, p. 182-200, 2015.

SOUZA, C. R. T.; COSTA SILVA, M.; ALVES, L. R. G. O game in situe a aprendizagem experiencial do jogar: desvendando seu potencial didático-pedagógico. In: Revista Metáfora Educacional, n. I5, p.77-95, 20 13. Disponível em: http://www.valdeci.bio.br/revista.html. Acesso em: 22 jun. 2019.

THE ECONOMIST. The Anthropocene: A man-made world. 20I I . Disponível em: https://www.economist.com/briefing/20I I/05/26/a-man-made-world. Acesso em: II fev. 2019.

VILCHES, A.; GIL-PÉREZ, D.; PRAIA, J. CTS a CTSA: educação por um futuro sustentável. In: DOS SANTOS, W. L. P.; AULER, D. (org.). CTS e educação científica desafios tendências e resultados de pesquisa. Brasília: EditoraUniversidade de Brasília, 201 I, p. 161-184.

WALKER, A.; LEARY, H. A problem based learning meta analysis: Differences across problem types, implementation types, disciplines, and assessment levels. Interdisciplinary Journal of Problem-based Learning, v. 3, n. I, p. 6, 2009.

ZABALA, A. A prática educativa: como educar. Porto Alegre, 1998. 